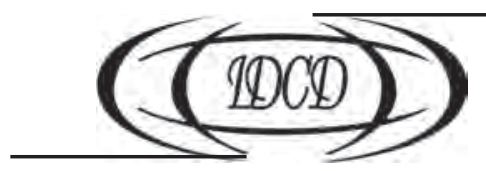

doi: $10.15407 /$ dse2016.02.039

УДК $613.7 ; 613.9 ; 314.04: 330.524(477)$

JEL Classification: J10, J17, J18

\title{
Н.А. РЫНГАЧ
}

д-р наук по гос. упр., глав. науч. сотруд.

Институт демографии и социальных

исследований им. М.В. Птухи НАН Украины

01032, Украина, Киев-32, бул. Т. Шевченко, 60

E-mail: n_ryngach@idss.org.ua

\section{ЭКОНОМИЧЕСКИЙ ЭКВИВАЛЕНТ ПОТЕРЬ ВСЛЕДСТВИЕ ПРЕЖДЕВРЕМЕННОЙ СМЕРТНОСТИ В УКРАИНЕ}

\begin{abstract}
Цель работы - осуществить оценку объема потерянных лет потенциальной жизни (ПЛПЖ) в связи с преждевременной смертностью в Украине с последующей конвертацией этих потерь в экономический эквивалент. На основе данных Государственной службы статистики Украины относительно распределения умерших по полу, возрасту и причинам смерти и макроэкономических показателей с помощью метода потенциальной демографии рассчитано абсолютное количество потерянных лет потенциальной жизни, недожитых из-за наступления преждевременной смерти. Показано, что объем потерянных лет потенциальной жизни в связи с преждевременной смертностью населения составил в 2013 году 3,031 млн человеко-лет (что можно сравнить с утратой трудового вклада на протяжении периода трудоспособного возраста целого города со стотысячным населением). Относительный показатель (индекс) ПЛПЖ составлял 7895,34 на 100 тыс. населения в возрасте до 65 лет. Выявлена существенная диспропориия потерь в зависимости от пола (по величине и структуре), и от причин смерти (лидирующая роль экзогенных причин). Рассчитанная в долларовом эквиваленте величина ВВП, недополученного в результате преждевременной смертности, превысила в 2013 г. 12 млрд \$ (из них из-за смертности в интервале 15-59 лет - свыше 10 млрд \$), ито составило 6,7 \% от величины номинального ВВП. При выборе в качестве эквивалента стоимости года жизни среднегодовой заработной платы цена ПЛПЖ составила 118, 75 млрдгривен. Обоснованы рекомендации практического применения методики оценки.
\end{abstract}

Ключевые слова: преждевременная смертность, потерянные годы потенциальной жизни, экономический эквивалент, ВВП на душу населения.

\section{Н.О. Рингач}

д-р наук $з$ держ. упр., голов. наук. співроб.

Інститут демографії та соціальних

досліджень ім. М.В. Птухи НАН України

01032, Україна, Київ-32, бул. Т. Шевченка, 60

E-mail: r_na@rambler.ru

\section{ЕКОНОМІЧНИЙ ЕКВІВАЛЕНТ ВТРАТ ВНАСЛІДОК ПЕРЕДЧАСНОЇ СМЕРТНОСТІ В УКРАЇНI}


Мета роботи - оцінити обсяг втрачених років потенційного життя (ВРПЖ) у зв'язку з передчасною смертністю в Україні з подальшою конвертацією цих втрат в економічний еквівалент. На основі даних Державної служби статистики України щьоо розподілу померлих за статтю, віком та причинами смерті і макроекономічних показників за допомогою методу потениійної демографії розраховано абсолютну кількість утрачених років потенційного життя, недожитих через настання передчасноі смерті. Показано, що обсяг втрачених років потенційного життя у зв'язку з передчасною смертністю населення досягав у 2013 році 3,031 млн людино-років (що можна порівняти зі втратою трудового внеску протягом періоду працездатного віку цілого міста зі стотисячним населенням). Відносний показник (індекс) ВРПЖ дорівнював 7895,34 на 100 тис. населення віком до 65 років. Виявлено суттєву диспропорцію втрат залежно від статі (за величиною і структурою), та від причин смерті (лідирують екзогенні причини). Розрахована в доларовому еквіваленті величина ВВП, недоотриманого внаслідок передчасної смертності, перевищила у 2013 р. 12 млрд \$ (з них через смертність в інтервалі 15-59 років - понад 10 млрд \$), що склало 6,7\% від величини номінального ВВП. У разі вибору в якості еквівалента вартості року життя величини середньорічної заробітної плати ціна втрачених років потенційного життя становила 118,75 млрд гривень. Обгрунтовано рекомендацї практичного застосування методики оцінки.

Ключові слова: передчасна смертність, втрачені роки потенційного життя, людино-роки, економічний еквівалент, ВВП на душу населення.

\section{N.A. Ryngach}

Dr. of Sciences (Public Governance/Administration), Leading research fellow

Ptoukha Institute for Demography and Social Studies

of the National Academy of Sciences of Ukraine

01032, Ukraine, Kyiv-32, Taras Shevchenko Blvd., 60

E-mail: n_ryngach@idss.org.ua

\section{ECONOMIC EQUIVALENT OF LOSSES DUE TO OF PREMATURE MORTALITY IN UKRAINE}

This paper means to make an assessment of the Years of Potential Life Lost (YPLL) due to premature mortality in Ukraine, with the conversion of the lost years into material equivalent. Taking into account the State Statistics Service of Ukraine data on deaths analysis by sex, age and cause and using macroeconomic indicators the author employs the potential demography method to calculate the absolute number of the years of potential life lost due to premature death. The study shows that the scope of potential years of life lost due to premature mortality was 3.031 million person-years in 2013. This may be compared with the loss of labor input at a working-age period in a city with a population of a hundred thousand people. The relative YPLL indicator (index) was 7895.34 per 1000 people under 65 years. A significant disproportion of the loss breakdown by sex (size and structure of losses), and by cause was discovered, with the leading role of exogenous causes established. In 2013 the GDP share lost due to premature mortality exceeded 12 billion USD (of which more than 10 billion USD - due to mortality at the age of 15-59years). This comprises $6.7 \%$ of the nominal GDP. As the annual average income was selected as the material equivalent of one year of life, the value of the lost years of potential life amounted to 118.75 billion hryvnias. Practical application of evaluation techniques is substantiated.

Key words: premature mortality, Years of Potential Life Lost, economic equivalent, person-years, Gross Domestic Product per capita.

Постановка проблемы. Общеизвестна зависимость экономического потенциала от количества и качества человеческих ресурсов. Трудовой потенциал любой страны формируется под влиянием одновременного воздействия трех демографических процессов. Рождаемость обеспечивает восполнение поколений, выбывающих по достижению пенсионного возраста (или умерших в интервале трудоспособного возраста); смертность (прежде всего преждевременная) сокращает количество людей, способных к труду. Миграция же способствует увеличению трудового потенциала (в случае привлекательности страны для иммигрантов), либо уменьшению - если 
граждане трудоспособного возраста ищут применения своим знаниям и умениям за пределами родины.

Несмотря на некоторое увеличение рождаемости, наблюдавшееся в последние годы, надеяться на обусловленное им возрастание доли населения трудоспособного возраста в ближайшей перспективе не приходится. Сегодня миграционная привлекательность нашей страны также невысока, поэтому предотвращение потерь вследствие ранних смертей в трудоспособном возрасте становится основным способом сохранения / увеличения трудового потенциала. Эффективные действия, направленные на борьбу с болезнями и травмами, приводящими к преждевременной смерти, одновременно положительно сказываются не только на количественных, но и на качественных его характеристиках.

Чтобы осознать масштаб утраты потенциальных лет человеческих жизней, обосновать необходимость превентивных мероприятий на национальном и региональном уровнях, необходима экономическая оценка потерь из-за преждевременной смертности.

Актуальность темы. В Украине наблюдается тенденция к сокращению численности населения трудоспособного возраста, и в ближайшей перспективе она вряд ли изменится. Так, согласно среднему варианту прогноза Института демографии и социальных исследований им. М.В. Птухи НАН Украины, к 2061 году численность населения в возрасте 15-59 лет сократится до 18,03 млн чел. (с 28,78 млн чел. в 2014 г.) [1]. Происходит не только сокращение абсолютного количества населения в этом возрастном интервале, но и изменение его доли относительно групп детей и граждан в возрасте, старше трудоспособного, со сдвигом баланса работников и иждивенцев. Так, по состоянию на 1 января 2014 года общая демографическая нагрузка в Украине составляла 595 на 1000 постоянного населения в возрасте 15-59 лет, причем соотношение между детьми, потенциально способными заменить в будущем работающих, и людьми, вышедшими из трудоспособного возраста, было в пользу последних (251 и 344 соответственно $^{1}$ ) [2]. С вхождением в рабочий возраст немногочисленных когорт молодых людей, родившихся в 1990-х, происходит качественное изменение характеристик трудоспособного населения, проявляющееся в постарении экономически активной его части, увеличении доли старшего трудоспособного возраста (45 лет и старше). Прогрессирующая недостаточность рабочей силы - один из главных стратегических рисков в сфере экономического роста. Высокий уровень преждевременной смертности (наряду с углублением постарения населения) в Украине является важным фактором потерь трудового потенциала. Почти каждый третий из умерших в 2013 г. (31,4 \%) не дожил до 65 лет, а показатель преждевременной смертности в Украине превышает такой в странах ЕС более чем вдвое.

Крайне необходима национальная стратегия, направленная на сохранение основного богатства страны - его населения. Для этого важно объективно оценить масштабы ежегодных демографических потерь, вызванных преждевременной смертностью - как реальных, так и потенциальных. Это возможно с помощью методики, которая оперирует не только статистикой действительных смертей, но и определяет объемы (в годах) потенциальной жизни, недожитой из-за наступления конкретных случаев смерти до определенного возраста. Связывая величину потерь (количество потерянных человеко-лет) и их стоимость (стоимость года жизни) можно опосре-

${ }^{1}$ Для сравнения: на 01.01.1999 - 356 и 412 соответственно. 
довано измерить недополученную выгоду в виде утраченной части национального продукта (например, части ВВП).

Анализ последних исследований и публикаций. Практика оценивания потерянных лет потенциальной жизни получила значительное распространение во многих странах во второй половине XX - начале XXI столетия [3-5]. Организация экономического сотрудничества и развития (OECD) также использует стандартизованный показатель PYLL (Potential Years of Life Lost) или YPLL (Years of Potential Life Lost) для оценки прогресса в снижении смертности и международных сравнений. В данном случае порог преждевременной смерти выше (до 70 лет), что объясняется большей продолжительностью жизни в странах OECD и более длинным периодом трудовой активности. Согласно оценке динамики (1990-2010 гг.) изменений стандартизованного по возрасту PYLL на 100 тыс. нас. в рамках исследования Global burden of disease-2010, Украина невыгодно отличалась от большинства стран Юго-Восточной Европы и Центральной Азии, где наблюдалось уменьшение потерь ${ }^{2}$. Регресс же Украины был оценен в 0,4 \%, тогда как даже наиболее отстающие бывшие советские республики демонстрировали минимальное снижение (Россия - на 0,2\%, а Казахстан - стабильность, правда, при самом высоком из 22 стран показателе) [6, С. 48].

Индекс потерянных лет потенциальной жизни может также выступать индикатором благосостояния населения, уменьшаясь в периоды экономического роста и процветания общества и увеличиваясь во время социальных трансформаций и конфликтов. Он часто используется Мировым Банком и Всемирной организацией здравоохранения как показатель, иллюстрирующий результативность социальноэкономической политики конкретной страны либо региона. В Украине оценка потерянных лет потенциальной жизни представлена в ряде научных работ таких отечественных ученых, как Кваша Е.А. (Kvasha Е.А.), Чепелевская Л.А. (Chepelevs'ka L.A.), Моисеенко P.A. (Moiseyenko R.A.), Нагорная А.M. (Nahorna A.M.), Колодяжная O.I. (Kolodyazhna O.I.) [7,8].

При переходе от чисто демографической оценки к экономической важен вопрос экономического эквивалента стоимости одного года человеческой жизни. Как правило, это разница между затратами, вложенными в человека, и получаемой (либо ожидаемой) от него отдачей в течение жизни. Такой подход оперирует балансом произведенных, накопленных и потреблённых человеком материальных благ и услуг. Итог зависит от возраста и учитывает как затраты, вложенные в человека, так и ожидаемую от него отдачу на протяжении его предстоящей жизни. В русле теории человеческого капитала экономический эквивалент стоимости человеческой жизни отображает не только инвестиции в индивидуума (государства, работодателя, общины, домохозяйства). В качестве их эффективности, выражаемой через отдачу, выступает показатель ВВП на душу населения [9].

Еще один подход - «доходный», учитывающий доход реальный и потенциальный (до конца жизни). При страховании и оценке профессиональных рисков такой подход базируется на субъективном оценивании (определении соотношения между риском для жизни и платой за него). Стоимость жизни выражалась суммой, за которую люди готовы пойти на дополнительный риск (либо наоборот, заплатить за снижение риска умереть). Самооценка людьми стоимости жизни также часто соответствует количеству годовых заработков, кратному величине средней продолжительности

\footnotetext{
${ }^{2}$ Наиболее выраженное для Турции - в два раза.
} 
жизни [10]. Медико-экономические методики расчета эффективности снижения преждевременной смертности оперируют такими критериями: потери чистого национального дохода; недополученный продукт; затраты на пенсии, пособия в случае потери кормильца и т. п. [10-13].

Измеряя настоящие и прогнозированные (до 2020 г.) потери вследствие смертности от рака в масштабах США ученые используют фиксированную стоимость года человеческой жизни, оцененную в $\$ 150000$ [14]. Д. Браун (D.W. Brown) определяет экономическую стоимость потерь в результате преждевременной смертности и инвалидности в результате насилия в странах - членах ВОЗ как долю от ВВП [15].

Естественно, доля ВВП на душу населения - это лишь приблизительная стоимость года жизни. Более точную экономическую оценку утраченного человеческого и трудового потенциала можно было бы получить, учитывая долю занятых в общественном производстве и величину среднегодового дохода с учетом надбавок к заработной плате (взносы работодателей на социальное обеспечение, медицинское социальное страхование, выплаты на частную пенсию) и т. д. Но подобная оценка в Украине и других постсоветских странах затруднена, так как официальная статистика часто не отражает истинного положения дел из-за распространения «теневой» экономики, «скрытой» занятости и необлагаемых доходов. Мы осознаем, что субъективная оценка жизни как наибольшей человеческой ценности намного выше, чем упущенная выгода из-за недовыработанного ВВП либо недополученного дохода. Разделяя утверждение И.Л. Трунова (I.L. Trunov) с соавторами, что «люди живут не для того, чтобы производить материальные блага; они производят материальные блага для того, чтобы жить» [16], тем не менее, используем для опосредованного оценивания потерь лет жизни экономические критерии.

Цель: дать оценку потерям лет потенциальной жизни вследствие преждевременной смертности в Украине в экономическом эквиваленте.

Для этого необходимо:

- рассчитать абсолютное количество потерянных лет потенциальной жизни (ПЛПЖ), недожитых из-за наступления преждевременной смерти, а также индекс ПЛПЖ на 100 тыс. населения, и осуществить международные сравнения;

- оценить вклад основных причин смерти в формирование ПЛПЖ и показать различия величины и структуры ПЛПЖ в зависимости от пола;

- измерить объем недополученного национального продукта и потерь потенциального дохода (с помощью разных подходов).

Для расчетов использован метод потенциальной демографии. Потерянные годы потенциальной жизни рассчитывались как сумма разностей (в годах) между пороговым значением возраста смерти и фактическим возрастом смерти всех умерших в течение года в возрастных интервалах младше порогового (то есть тех, кто умер до достижения указанного возраста) [17]. Показатель (индекс) лет потерянной потенциальной жизни представляет собой годы утраченной потенциальной жизни на 100 тыс. человек в определенном возрасте (до 65 лет - в нашем случае) (1):

$$
\frac{\Sigma(65-\text { age of death }) \times \text { number of deaths at each age }}{\text { Number of people ades } 65 \text { and younger }} \times 100,100
$$


Для достоверности оценки при сравнении стран и территорий, а также анализа динамики применяется стандартизация по возрасту.

В качестве порогового возраста дожития выбрана величина 65 лет. Мы также использовали в процессе оценке потерь и единый интервал 15-59 лет для мужчин и женщин как трудоспособный возраст, сознательно игнорируя существующие в Украине законодательно определенные различия границ пенсионного возраста по полу для возможности проведения адекватного сравнения этих групп.

В качестве стоимости года жизни приняты: размер ВВП, приходящегося на душу населения в конкретном году (в национальной валюте и в долларах США), а также размер среднегодовой зарплаты (в гривнах). Информационной базой исследования стали данные официальной статистики (Государственной службы статистики Украины) по итогам 2013 года, а именно демографические и макроэкономические показатели.

Результаты исследования. В Украине абсолютное количество потерянных лет потенциальной жизни, недожитых из-за наступления преждевременной смерти, составило в 2013 году 3,031 млн человеко-лет.

Вклад основных причин в общий массив потерянных лет потенциальной жизни достаточно сильно различается в зависимости от пола (табл. 1). Так, доля неестественных смертей у украинских мужчин практически вдвое больше, чем у женщин. Почти 40 \% ПЛПЖ у мужчин и четверть - у женщин детерминированы экзогенными причинами (сумма внешних причин и инфекционных и паразитарных болезней).

Соответственно показатель потерянных лет потенциальной жизни (ПЛПЖ) вследствие преждевременной (до 65 лет) смертности составил в 2013 г. 7895,34 на 100 тыс. населения соответствующего возраста, при этом почти 75 \% потерь сформировано четырьмя основными классами - внешними причинами, болезнями системы кровообращения, новообразованиями и инфекционными болезнями (рисунок).

Для адекватного международного сравнения были пересчитаны показатели с пороговым значением возраста дожития в 70 лет и последующей стандартизацией по возрасту, которые достигали в 2013 г. 13520 и 4996 на 100 тыс. для мужчин и женщин соответственно (рисунок). Этот показатель для мужчин в Украине более чем втрое выше, чем в странах Организации экономического сотрудничества и развития (OECD), для женщин разница была менее выраженной (в 2,1 раза). При этом отдельно взятый показатель для украинских мужчин оказался большим, чем сумма значений для обоих полов в странах OECD.

Таблица 1. Структура ПЛПЖ по основным причинам, \%, мужчины и женщины, Украина, 2013 г.

\begin{tabular}{|c|c|l|c|c|}
\hline $\begin{array}{c}\text { Ранговое } \\
\text { место }\end{array}$ & Мужчины & \multicolumn{1}{|c|}{ Причина смерти } & Женщины & $\begin{array}{c}\text { Ранговое } \\
\text { место }\end{array}$ \\
\hline II & 25,2 & Болезни системы кровообращения & 20,9 & II \\
\hline I & $\mathbf{2 8 , 3}$ & Внешние причины & 15,1 & III \\
\hline III & 11,2 & Новообразования & $\mathbf{2 3 , 1}$ & I \\
\hline IV & 9,4 & Болезни органов пищеварения & 10,0 & IV \\
\hline V & 9,2 & Инфекционные и паразитарные болезни & 8,9 & V \\
\hline
\end{tabular}

Источник: авторские расчеты по данным Госстата Украины. 


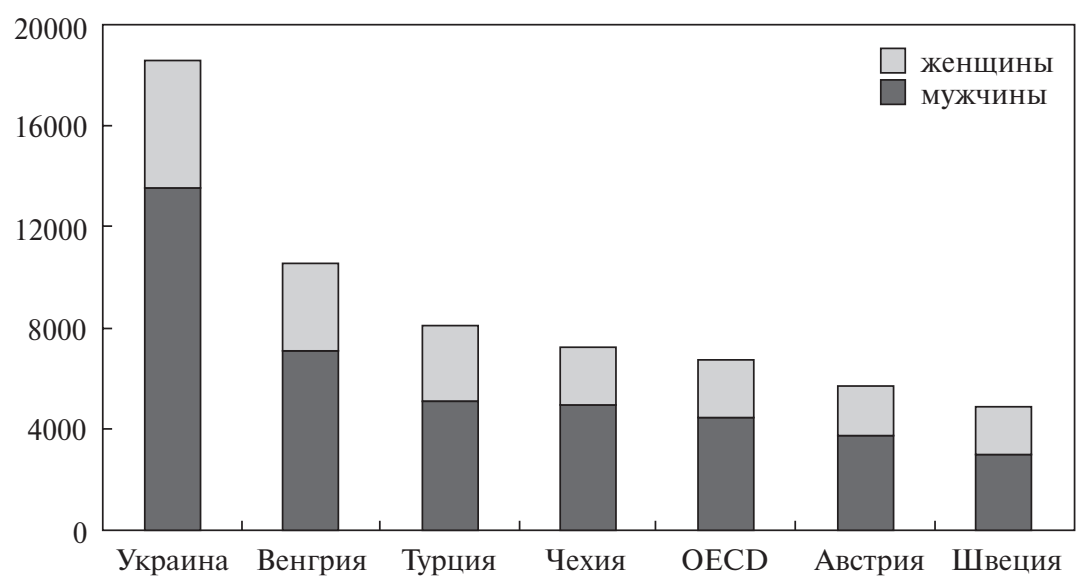

Рис. Показатель потерянных лет потенциальной жизни, на 100 тыс. нас. 0-69 лет, 2013 г.

Источник: OECD Health Statistics (database): November 2014 update (http://www.oecd.org/els/health-systems/oecdhealth-statistics-2014-frequently-requested-data.htm), авторские расчеты.

Расчеты свидетельствуют о весомости экономического ущерба из-за высокого уровня преждевременной смертности. Для его оценки мы использовали несколько подходов. Как уже отмечалось, недожитые годы оборачиваются непроизведённым национальным продуктом. Так, при том, что в среднем на каждого гражданина Украины в 2013 году приходилась часть валового внутреннего продукта (ВВП) в размере 32 028,5 гривен, или 4007,1 \$, более 3 млн ПЛПЖ были оценены минимум в 90,4 млрд гривен, причем большая их часть обусловлена смертями украинских мужчин (почти $71 \%)$. Напомним, что согласно нашим более ранним расчетам (2006 г.) абсолютное количество ПЛПЖ было большим и составляло 4 млн человеко-лет. Это объясняется более высоким уровнем преждевременной смертности. Однако показатель ВВП на душу населения в 2006 г. был в 2,5 раза меньше, т. е. 11,5 тыс. гривен, соответственно потери были оценены в 47,9 млрд гривен. Отталкиваясь от величины номинального ВВП (в фактических ценах) в каждом конкретном году, мы оценили различия в относительной весомости потерь лет потенциальной жизни в разные периоды времени. Как видно из табл. 2, несмотря на относительно меньшую стоимость (в млрд грн) потерь в 2006 г., они тем не менее составляли наибольшую долю от ВВП - 8,8 \%. В 2011-2013 гг. эта доля несколько уменьшилась, однако подчеркнем, что ее значение почти вдвое выше официальных бюджетных расходов на здравоохранение.

Таблица 2. Экономическая оценка потерь вследствие преждевременной смертности, 2006, 2011, 2013 гг.

\begin{tabular}{|l|c|c|c|}
\hline \multicolumn{1}{|c|}{ Показатель } & $\mathbf{2 0 0 6}$ & $\mathbf{2 0 1 1}$ & $\mathbf{2 0 1 3}$ \\
\hline $\begin{array}{l}\text { Количество потерянных лет потен- } \\
\text { циальной жизни, млн человеко-лет }\end{array}$ & 4,165 & 3,134 & 3,031 \\
\hline $\begin{array}{l}\text { Оценка потерь в виде недополучен- } \\
\text { ного ВВП, млрд грн }\end{array}$ & 47,9 & 90,4 & 97,1 \\
\hline Доля от ВВП,\% & 8,8 & 6,7 & 6,7 \\
\hline
\end{tabular}

Источник: авторские расчеты по данным Госстата Украины. 
Таблица 3. Оценка потерь вследствие преждевременной смертности от основных причин, оба пола, 2013 г.

\begin{tabular}{|c|c|c|c|c|c|}
\hline \multirow{2}{*}{$\begin{array}{c}\text { Причины смерти (класс } \\
\text { по МКБ-10) }\end{array}$} & \multicolumn{2}{|c|}{$\begin{array}{c}\text { Количество потерянных } \\
\text { лет потенциальной жизни }\end{array}$} & \multicolumn{2}{|c|}{$\begin{array}{c}\text { Потери в виде недополу- } \\
\text { ченного ВВП, в млрд \$ }\end{array}$} & \multirow{2}{*}{$\begin{array}{c}\text { Доля потерь } \\
\text { вследствие } \\
\text { смертности } \\
\text { в интервале } \\
\text { 15-59 лет, } \\
\%\end{array}$} \\
\hline & 0-64 года & 15-59 лет & 0-64 года & 15-59 лет & \\
\hline $\begin{array}{l}\text { Все причины, в том } \\
\text { числе: }\end{array}$ & 3031195 & 2590652,5 & 12,146 & 10,038 & 85,5 \\
\hline $\begin{array}{l}\text { I. Инфекционные и } \\
\text { паразитарные болезни } \\
\text { (А00-B99) }\end{array}$ & 275810 & 261070 & 1,105 & 1,046 & 94,7 \\
\hline $\begin{array}{l}\text { II. Новообразования } \\
\text { (C00-D } 48 \text { ) }\end{array}$ & 444692,5 & 392850 & 1,782 & 1,574 & 88,3 \\
\hline $\begin{array}{l}\text { IX. Болезни системы } \\
\text { кровообращения (I00- } \\
\text { I99) }\end{array}$ & 725647,5 & 639292,5 & 2,908 & 2,562 & 88,1 \\
\hline $\begin{array}{l}\text { Х. Болезни органов } \\
\text { дыхания (J00-J99) }\end{array}$ & 117075 & 105082,5 & 0,469 & 0,405 & 86,2 \\
\hline $\begin{array}{l}\text { ХІ. Болезни органов пи- } \\
\text { щеварения (K00-K93) }\end{array}$ & 288852,5 & 277932,5 & 1,158 & 1,113 & 96,2 \\
\hline $\begin{array}{l}\text { XX. Внешние причины } \\
\text { (V01-Y98) }\end{array}$ & 740922,5 & 691375,0 & 2,969 & 2,770 & 93,3 \\
\hline
\end{tabular}

Источник: авторские расчеты по данным Госстата Украины.

Также были произведены расчеты и оценка потерь вследствие преждевременной смертности в разрезе основных причин для всего населения и населения в возрасте 15-59 лет. Показано, что большинство $(85,5$ \%) всех потерь вследствие преждевременной смертности сосредоточено в интервале трудоспособного возраста (табл. 3 ). Доля же таких причин, как внешние (травмы, отравления, несчастные случаи), инфекционные и паразитарные болезни, а также болезни органов пищеварения превышала даже $90 \%$ !

Если же следовать «доходному» подходу и принять в качестве эквивалента стоимости года жизни величину среднегодовой заработной платы, составляющей в 2013 году 39180 грн, то стоимость потерянных украинцами лет потенциальной жизни можно оценить в 118,75 млрд гривен.

Мы воспользовались еще одним подходом к оценке потерь. Если предположить, что человек начинает трудиться с получением паспорта и продолжает работать до достижения пенсионного возраста, то его трудовой стаж составит 44 года. Но такое допушение оказывается верным лишь для части населения. Абсолютное большинство приступает к труду после 20 (а то и 25) лет. Неизбежно часть времени в интервале между 16 и 60 годами по тем или иным причинам выпадает из периода трудовой активности. В Украине, как показывает практика, трудовой период жизни длится в среднем 31-32 года. Таким образом, ежегодную потерю более трех миллионов человеко-лет из-за преждевременной смертности можно сравнить с утратой трудового вклада целого города со стотысячным населением. Даже если игнорировать детей и 
сделать перерасчет для потерь в интервале 15-59 лет, количество жителей «утраченного» города составило бы более 83 тысяч.

Область применения результатов. Оценка потерь лет потенциальной жизни с конвертацией в экономический эквивалент как способ взвесить потери, определить направления вмешательств, становится важным инструментом стратегического планирования, принятия научно обоснованных политических решений и отслеживания эффективности их реализации. На постсоветском пространстве примером реального использования расчетов показателя потерянных лет потенциальной жизни для усовершенствования методов управления на местном и региональном уровнях стал проект «Здоровые люди», реализованный в 2012-2014 гг. в Санкт-Петербурге при поддержке Европейской Комиссии. Проект продемонстрировал возможность локального выявления наиболее значимых проблем здоровья населения, дальнейшего планирования реалистичных мер вмешательства в определенных приоритетных областях, с последующим результатом - снижением преждевременной смертности от предотвратимых причин в пилотном районе Санкт-Петербурга, а также в городе в целом [18].

Выявленная выраженная половая диспропорция по величине (индекс у мужчин более чем в 2,5 раза выше), и структуре (лидирующая роль в формировании потерь у мужчин внешних причин, у женщин - новообразований) предопределяет различия в подходах к снижению количества потерь лет потенциальной жизни, и соответственно, социально-экономических убытков из-за преждевременной смертности.

Выводы. Вследствие высокой преждевременной смертности Украина теряет непозволительно большие объемы потенциальных лет жизни по сравнению с развитыми странами (особенно мужчин), имеются также структурные различия с большей весомостью экзогенных причин смерти.

Рассчитанная в долларовом эквиваленте величина недополученного в результате преждевременной смертности ВВП превысила в 2013 году 12 млрд \$ (из них из-за смертности в интервале 15-59 лет - более 10 млрд \$), что можно представить как $6,7 \%$ от величины номинального ВВП.

Если же принять в качестве эквивалента стоимости года жизни величину среднегодовой заработной платы в 2013 г., то цена потерянных лет потенциальной жизни составила 118,75 млрд гривен. Кроме того, ежегодную потерю более трех миллионов человеко-лет из-за преждевременной смертности можно сравнить с утратой трудового вклада на протяжении всего периода трудоспособного возраста (с 16 до 60 лет) целого города со стотысячным населением.

В современном мире именно человек - основной фактор развития экономики и общества. Уменьшение количества и ухудшение качества человеческих ресурсов - это одна из наиболее острых проблем социально-экономического развития в любой стране, требующая как своевременного осознания, так и разработки действенных превентивных мер. Таким образом, экономическая оценка потерь лет потенциальной жизни служит существенным шагом на пути к минимизации таких потерь и сохранению/увеличению национального богатства.

\section{ЛІТЕРАТУРА}

1. Прогноз чисельності населення України (оновлено серпень 2014) [Электронный ресурс]. - Режим доступа : http://www.idss.org.ua/index.html\#

2. Населення України за 2013 рік: Демографічний щорічник / Державна служба статистики України. - К., 2014. - С. 53. 
3. Gardner J.W. Years of potential life lost (YPLL) - what does it measure? / J.W. Gardner, J.S. Sanborn // Epidemiology. - 1990. - Jul; 1(4). - P. 322-329.

4. Premature mortality in the United States: public health issues in the use of years of potential life lost // MMWR (Morb Mortal Wkly Rep.) - 1986. - № 35. - P. 1S-11S.

5. Vienonen M. From Shadow into Light: Use of PYLL-indicator (potential years of life lost) as catalyst for health in all policies at local and regional level / Vienonen M., Vohlonen I. // Abstracts of 9th European IUHPE Health Promotion Conference (Tallinn, 2012) [Electronic resource]. - Access mode : https://abstracts.conference-expert.eu/iuhpe2012/files/indexedab.html?work_info $=160$

6. Глобальное бремя болезней (Global burden of disease): Порождение доказательств, направление политики: региональное издание для Европы и Центральной Азии. - WA, 2013. - 70 c.

7. Колодяжна О.I. Визначення втрачених років здорового життя від професійних захворювань за методом DALY / Колодяжна O.I., Нагорна А.M. // Укр. журнал з проблем медицини праці. 2013. - № 2 (35). - C. 11-15.

8. Рынгач Н.А. Оценка потерянных лет потенциальной жизни вследствие младенческой смертности / Рынгач Н.А., Моисеенко Р.А. // Восточноевропейский журнал общественного здоровья. 2013. - Спецвып. на рус. яз. - С. 81-84.

9. Нифантова Р.В. Современные методические подходы в оценке стоимости человеческой жизни / Р.В. Нифантова, С.Е. Шипицына // Экономика региона. - № 3. - 2012. - С. 289-294.

10. Общественное здоровье и экономика : кол. моногр. / Отв. ред. Б.Б. Прохоров. - М.: МАКС Пресс, 2007. - 292 c.

11. Фролов О.П. Стоимость человеческой жизни в России и за рубежом / О.П. Фролов // Справочник специалиста по охране труда. - 2010. - № 2. [Электронный ресурс]. - Режим доступа : http://www.mcfr.ru/journals/63/190/18130/18210/

12. Шмаков Д.И. Оценка экономического ущерба от потерь здоровья населения в России и ее регионах : Дис. ... канд. экон. наук : 08.00 .05 : М., 2004. - 154 с.

13. Прохоров Б.Б. Причины гибели людей в мирное время и экономическая оценка стоимости потерь / Б.Б. Прохоров, Д.И. Шмаков // Проблемы прогнозирования. - 2013. - № 3. - С. 139-147.

14. Estimates and Projections of Value of Life Lost From Cancer Deaths in the United States / K. R. Yabroff, C. J. Bradley, A. B. Mariotto, M. L. Brown, and E. J. Feuer // J Natl Cancer Inst. - 2008, Dec 17. - № 100 (24). - P. 1755-1762.

15. Brown D.W. Economic value of disability-adjusted life years lost to violence: estimates for WHO Member States / D.W. Brown // Rev Panam Salud Publica. - 2008. - № 24 (3). - P. 203-209.

16. Трунов И.Л., Айвар Л.К., Харисов Г.Х. Эквивалент стоимости жизни [Электронный ресурс]. Режим доступа : http://www.trunov.com/content.php?act=showcont\&id=1858.

17. Principles of Epidemiology (Second edition) Self-Study Course 3030-G CDC / R. Dicker, N. Gathany, P. Anderson, B. Segal, S. Smith, Ph. Thompson / US Department of Health \& Human Services, 12/92 [Electronic resource]. - Access mode : http://pubhealth.spb.ru/EpidD/

18. Здоровые люди: управление изменениями через мониторинг и действия : сборник материалов международного проекта. - СПб : Центр РНО, 2014. - 178 с.

\section{REFERENCES}

1. Prohnoz chyselnosti naselennia Ukrainy (onovleno serpen 2014) [Population forecast for Ukraine (last updated August 2014)]. idss.org.ua. Retrieved from http://www.idss.org.ua/index.html\# [in Russian].

2. Naselennia Ukrainy za 2013 rik: Demohrafichnyi shchorichnyk [Population Of Ukraine 2013: Demographic Yearbook] (2014). Kyiv : State Statistics Service of Ukraine [in Ukrainian].

3. Gardner, J.W. \& Sanborn, J.W. (1990). Years of potential life lost (YPLL) - what does it measure? Epidemiology, 1(4), 322-329 [in English].

4. Premature mortality in the United States: public health issues in the use of years of potential life lost (1986). MMWR (Morb Mortal Wkly Rep.) [in English].

5. Vienonen, M. \& Vohlonen I. (2012). From Shadow into Light: Use of PYLL-indicator (potential years of life lost) as catalyst for health in all policies at local and regional level / Vienonen M., // Abstracts of 9th European IUHPE Health Promotion Conference. Tallinn. abstracts.conference-expert.eu. Retrieved from https://abstracts.conference-expert.eu/iuhpe2012/files/indexedab.html?work_info=160 [in English]. 
6. Globalnoe bremya bolezney: Porozhdenie dokazatelstv, napravlenie politiki : regionalnoe izdanie dlya Evropyi $i$ Tsentralnoy Azii. [Global burden of disease: Generating evidence, policy area: Regional edition for Europe and Central Asia]. (2013). WA [in Russian].

7. Kolodyazhna, O.I. \& Nahorna, A.M. (2013). Vyznachennya vtrachenykh rokiv zdorovoho zhyttya vid profesiynykh zakhvoryuvan' za metodom DALY [Definition of lost years of healthy life from occupational diseases by DALY]. Ukrainskyi zhurnal z problem medytsyny pratsi - Ukrainian Journal of the problems Labour Medicine, 2(35), 11-15 [in Ukrainian].

8. Ryngach, N.A. \& Moiseenko, R.A. (2013). Ocenka poterjannyh let potencial'noj zhizni vsledstvie mladencheskoj smertnosti [Assessment of potential life years lost due to infant mortality]. Vostochnoevropejskij zhurnal obshhestvennogo zdorov'ja - East European Journal of Public Health, 81-84 [in Russian].

9. Nifantova, R.V \& Shipitsyina, S.E. (2012). Sovremennyie metodicheskie podhodyi v otsenke stoimosti chelovecheskoy zhizni [Modern methodological approaches in the evaluation of the value of human life]. Ekonomika regiona - Economy of region, 3, 289-294 [in Russian].

10. Prokhorov, B.B. (Eds.). (2007). Obshchestvennoye zdorovye i economika [Publis health and economics]. Moscow : MAX Preess [in Russian].

11. Frolov, O.P. (2010). Stoimost chelovecheskoy zhizni v Rossii i za rubezhom [The cost of human life in Russia and abroad]. Spravochnik spetsialista po ohrane truda - Manual labor protection specialist, 2. Retrieved from http://www.mcfr.ru/journals/63/190/18130/18210/ [in Russian].

12. Shmakov, D.I. (2004). Otsenka ekonomicheskogo uscherba ot poter zdorovya naseleniya v Rossii i ee regionah [Assessment of the economic impact of health losses in Russia and its regions]. Extended abstract of candidate's thesis. Moscow [in Russian].

13. Prohorov, B.B. \& Shmakov, B.B. (2013). Prichinyi gibeli lyudey v mirnoe vremya i ekonomicheskaya otsenka stoimosti poter [Causes of deaths in peacetime and economic valuation loss]. Problemyi prognozirovaniya - Problems of forecasting, 3, 139-147 [in Russian].

14. Yabroff, K.R., Bradley, C.J., Mariotto, A.B., Brown, M.L. \& Feuer, E.J. (2008). Estimates and Projections of Value of Life Lost From Cancer Deaths in the United States. J Natl Cancer Inst, 100(24), 1755-1762 [in English].

15. Brown, D.W. (2008). Economic value of disability-adjusted life years lost to violence: estimates for WHO Member States. Rev Panam Salud Publica, 24(3), 203-209 [in English].

16. Trunov, I.L., Aivar, L.K. \& Kharisov, G.Kh. Ekvivalent stoimosti zhizni [Equivalent of life cost]. (n.d.). trunov.com. Retrieved from http://www.trunov.com/content.php?act=showcont\&id=1858 [in Russian].

17. Dicker, R., Gathany, N., Anderson, P., Segal, B., Smith S. \& Thompson, Ph. Principles of Epidemiology (Second edition) Self-Study Course 3030-GCDC. US Department of Health \& Human Services, 12/92. (n.d.). pubhealth.spb.ru. Retrieved from http://pubhealth.spb.ru/EpidD/ [in English].

18. Sbornik materialov mezhdunarodnogo proekta «Zdorovyie lyudi: upravlenie izmeneniyami cherez monitoring $i$ deystviya» [Collected materials of the international project «Healthy people: change management through monitoring and action»]. (2014). SPb : Tsentr RNO [in Russian].

Статья поступила в редакцию 19.05.2016. 